\title{
Effect of a Chitosan Gel on Hemostasis and Prevention of Adhesion After Endoscopic Sinus Surgery
}

\author{
Young-Jun Chung ${ }^{1} \cdot$ Se-Young An ${ }^{1} \cdot$ Je-Yeob Yeon ${ }^{2} \cdot$ Woo Sub Shim² $\cdot$ Ji-Hun Mo ${ }^{1}$ \\ ${ }^{1}$ Department of Otorhinolaryngology-Head and Neck Surgery, Dankook University College of Medicine, Cheonan; \\ ${ }^{2}$ Department of Otorhinolaryngology-Head and Neck Surgery, Chungbuk National University College of Medicine, Cheongju, Korea
}

Objectives. Postoperative bleeding and adhesion formation are the two most common complications after endoscopic sinus surgery (ESS). The former sometimes can be life threatening and the latter is the most common reason requiring revision surgery. This study was designed to evaluate the effect of newly developed chitosan gel (8\% carboxymethyl chitosan, Surgi shield) on hemostasis and wound healing after ESS.

Methods. A prospective, randomized, double-blind controlled trial was conducted in 33 patients undergoing symmetric ESS. At the conclusion of the operation, Surgi shield was randomly applied on one side of the nasal cavity, with the opposite side acting as control and the bleeding quantity of the surgical field was evaluated every 2 minutes. And then, Merocel was placed in the ethmoidectomized areas of the both sides. Five milliliters of Surgi shield was applied to the Merocel of intervention side and saline was applied to the other side. Merocel in both nasal cavities was removed and $5 \mathrm{~mL}$ of Surgi shield was applied again to the intervention side on the second day after surgery. The nasal cavity was examined using a nasal endoscope and the degree of adhesion, crusting, mucosal edema, infection, and granulations were graded at 1,2, and 4 weeks after surgery.

Results. Complete hemostasis was rapidly achieved in the Surgi shield applied side compared with the control side at 2,4 , 6,8 , and 10 minutes after application of Surgi shield $(P=0.007, P=0.004, P<0.001, P=0.001$, and $P<0.001$, respectively). There were significantly less adhesions on the Surgi shield applied side at postoperative 1,2 , and 4 weeks $(P=0.001, P<0.001$, and $P<0.001$, respectively). The degree of mucosal edema, infection, crusting, or granulation formation assessed by the endoscopic features in the Surgi shield applied side was not significantly different from that of the control side $(P>0.05)$. No adverse effects were noted in the patient series.

Conclusion. Surgi shield containing chitosan can be used safely to achieve rapid hemostasis immediately after ESS and to prevent adhesion formation.

Keywords. Chitosan; Endoscopy; Wound Healing; Hemostasis; Adverse Effects

- Received April 13, 2015

Revised June 8, 2015

Accepted June 9, 2015

- Corresponding author: Ji-Hun Mo

Department of Otorhinolaryngology-Head and Neck Surgery, Dankook

University College of Medicine, 119 Dandae-ro, Dongnam-gu, Cheonan

31116, Korea

Tel: +82-41-550-3933, Fax: +82-41-556-1090

E-mail: jihunmo@gmail.com

- Co-Corresponding author: Woo Sub Shim

Department of Otorhinolaryngology-Head and Neck Surgery, Chungbuk

National University College of Medicine, 1Chungdae-ro, Seowon-gu,

Cheongju 28644, Korea

Tel: +82-43-269-6157, Fax: +82-43-265-6157

E-mail: hwatas@chungbuk.ac.kr

\section{INTRODUCTION}

Endoscopic sinus surgery (ESS) has become a widely accepted procedure for the treatment of medically refractory chronic rhinosinusitis (CRS) and nasal polyps [1]. Postoperative bleeding and adhesion formation in the middle meatus are the two most common complications after ESS. The former is commonly encountered in the early postoperative period and sometimes can be life-threatening due to airway compromise. The latter occurs in between $11 \%$ and $54 \%$ and is the most common reason for revision surgery [2-6].

Copyright () 2016 by Korean Society of Otorhinolaryngology-Head and Neck Surgery.

This is an open-access article distributed under the terms of the Creative Commons Attribution Non-Commercial License (http://creativecommons.org/licenses/by-nc/4.0)

which permits unrestricted non-commercial use, distribution, and reproduction in any medium, provided the original work is properly cited. 
Along with the use of mucosal preservation techniques, numerous techniques including suture medialization, partial resection of the middle turbinate, and nasal packing in the middle meatus have been used to prevent postoperative adhesion formation. Among these, nasal packing with nonabsorbable or biodegradable materials remains the most common procedure to prevent adhesion formation and postoperative bleeding.

Normal wound healing is necessary to achieve surgical success. However, some patients experience impaired wound healing postoperatively, requiring further surgery. Mucosal wound healing is a highly ordered and well-coordinated process and involves proliferation of inflammatory cells to the wound, epithelial closure, cell differentiation, matrix deposition and remodeling. Undesirable mucosal healing is related with the blood accumulation in the middle meatus [7]. Wound healing is intimately affected by inflammation and fibrosis which are strongly activated by coagulation cascade [8].

Chitosan is a natural product found in the shells of marine crustaceans. Chemically, it is a polysaccharide biopolymer obtained by alkaline deacetylation of natural chitins. Chitosan has been known to have biomedically useful properties, including its ability to rapidly clot blood [9], hypoallergenicity [10], antimicrobial effects [11], and solubility in the acidic environment of epithelial wound healing [12]. As a result, chitosan-based compounds appeared attractive for use intraoperatively during ESS [13], and has shown promising results in a human study [14]. Recently, new form of chitosan gel (Surgi shield, D. med, Seoul, Korea) that contains $8 \%$ chitosan and $92 \% \mathrm{H}_{2} \mathrm{O}$ was developed to be easily applied after ESS.

In this study, we aimed to evaluate the effect of Surgi shield on hemostasis and wound healing after ESS in medically refractory CRS patients.

\section{MATERIALS AND METHODS}

\section{Subjects and inclusion/exclusion criteria}

A prospective, randomized, double-blinded, placebo-controlled trial (ClinicalTrials.gov Identifier: NCT01895933) was conduct-

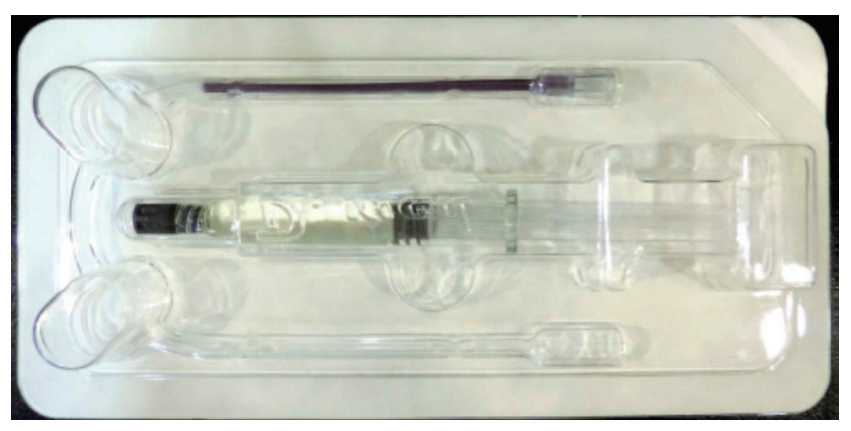

Fig. 1. Surgi shield (D. med, Seoul, Korea) contained in a syringe. ed at two tertiary academic hospitals in South Korea. Patients aged 20 years or older with CRS with or without polyps who underwent bilateral symmetric ESS from March 2012 to April 2013 were recruited to take part in this study. All patients received oral antibiotic therapy for more than three months prior to computed tomography (CT) scans and had evidence of significant disease on CT imaging. Patients meeting inclusion criteria were enrolled consecutively into this randomized, controlled, and blinded study. Ethics approval was obtained from the Internal Review Board of Dankook University Hospital (1103-022) and Chungbuk National University Hospital (D-2011-03-003). Patients were excluded if they were younger than 20 years, were ineligible for informed consent, had a severe septal deviation or massive polyposis, had systemic disease, had any history of allergy to chitin or asthma, or had a history of previous sinus surgery. Patients who underwent asymmetrical sinus surgery were also excluded.

\section{Study medical agent}

Chitosan gel (Surgi shield) is a mixture of $8 \%$ of carboxymethyl chitosan and $92 \%$ of $\mathrm{H}_{2} \mathrm{O}$ and was obtained from D. med (Fig. 1) and was applied alone and together with Merocel (Medtronic Xomed, Jacksonville, FL, USA) nasal packs on the ethmoid cavity after ESS. This clinical trial was sponsored by D. med.

\section{Study design}

Informed consent was obtained from all patients prior to enrollment. Following induction of general anesthesia, the nose was prepared with topical 1:1,000 epinephrine to decongest the nasal mucosa. Submucosal injection of 1:100,000 epinephrine was performed to control bleeding at the incision site at the beginning of the operation. ESS was then performed bilaterally using meticulous mucosal sparing techniques with powered instrumentation by 4 surgeons (YJC, JYY, WSS, and JHM) who are experts in ESS.

The side of Surgi shield application was randomly assigned using random number generation method, with the opposite

Table 1. Boezaart surgical field grading scale

\begin{tabular}{ll}
\hline Grade & \multicolumn{1}{c}{ Assessment } \\
\hline 0 & No bleeding (cadaveric conditions) \\
1 & Slight bleeding - no suctioning required \\
2 & Slight bleeding - occasional suctioning required \\
3 & $\begin{array}{c}\text { Slight bleeding - frequent suctioning required; bleeding } \\
\text { threatens surgical field a few seconds after suction is removed }\end{array}$ \\
4 & $\begin{array}{l}\text { Moderate bleeding - frequent suctioning required and bleeding } \\
\text { threatens surgical field directly after suction is removed }\end{array}$ \\
5 & $\begin{array}{l}\text { Severe bleeding - constant suctioning required; bleeding } \\
\text { appears faster than can be removed by suction; surgical field } \\
\text { severely }\end{array}$ \\
&
\end{tabular}

Adapted from Boezaart et al. Can J Anaesth. 1995 May;42(5 Pt 1):373-6, with permission of Springer [15]. 
side acting as control (no application of Surgi shield). Immediately after completion of surgery on each nasal cavity, the quality of the surgical field regarding bleeding and visibility was assessed on a numeric rating scale introduced by Boezaart et al. [15] (Table 1). On the intervention side, immediately after baseline surgical grade scoring, $5 \mathrm{~mL}$ of Surgi shield was applied to the surgical site including the middle meatus, frontal recess, ethmoid roof, and ethmoid cavity. On the control side no material was applied. Application of Surgi shield was performed by the resident physician who did not perform the surgery and video was recorded for 10 minutes to evaluate surgical field grading later. A surgical field grade score was assessed by 2 surgeons every 2 minutes until the cessation of bleeding or until 10 minutes had elapsed with the recorded video which did not contain personal information. Therefore, the surgeons were not aware which side was applied with Surgi shield in this study.

After the recording of the surgical field for 10 minutes, Merocel was placed in the ethmoidectomy cavity of the both sides. Five milliliters of Surgi shield was then applied on the surface of the Merocel in intervention side, resulting in inflation of the Merocel and saline was applied to the other control side. Merocel in both nasal cavities was removed and $5 \mathrm{~mL}$ of Surgi shield was applied again to the intervention side on the second day af-

Table 2. An ordinal scale of outcome measures evaluated by nasal endoscopy

\begin{tabular}{|c|c|}
\hline Outcome measure & Description \\
\hline \multicolumn{2}{|l|}{ Mucosal edema } \\
\hline 0 & No visible mucosal edema \\
\hline 1 & $\begin{array}{l}\text { Mild mucosal edema without obliteration of the } \\
\text { ethmoid cavity }\end{array}$ \\
\hline 2 & $\begin{array}{l}\text { Severe mucosal edema obliterating most of the } \\
\text { ethmoid cavity }\end{array}$ \\
\hline 3 & Frank polyposis \\
\hline \multicolumn{2}{|c|}{ Evidence of infection } \\
\hline 0 & No visible evidence of infection \\
\hline 1 & Mild mucopurulent drainage \\
\hline 2 & $\begin{array}{l}\text { Gross mucopurulent drainage with obvious frank } \\
\text { infection }\end{array}$ \\
\hline \multicolumn{2}{|l|}{ Crusting } \\
\hline 0 & Absent \\
\hline 1 & Mild \\
\hline 2 & severe \\
\hline \multicolumn{2}{|l|}{ Granulations } \\
\hline 0 & No visible granulations \\
\hline 1 & Mild \\
\hline 2 & Moderate \\
\hline 3 & Severe \\
\hline \multicolumn{2}{|l|}{ Adhesion } \\
\hline 0 & No adhesion present \\
\hline 1 & $<25 \%$ of middle turbinate height \\
\hline 2 & Between $25 \%$ and $50 \%$ of middle turbinate height \\
\hline 3 & $>50 \%$ of middle turbinate height \\
\hline
\end{tabular}

ter surgery. These procedures were also performed by resident physician and the patients were discharged.

Postoperatively, all patients were scheduled for follow-up visits at 1,2 , and 4 weeks after surgery. All patients received a course of antibiotics and were instructed to perform normal saline irrigation 2 to 3 times daily on each side. The nasal cavity was examined and photographed using a nasal endoscope for grading of crusting, mucosal edema, infection, and granulations at each visit. All parameters were graded using an ordinal scale (Table 2). Adhesion was graded based on the percentage of the vertical height of the middle turbinate taken up by the adhesion (Table 2). All grades were evaluated by 2 surgeons blinded to the application of the agents using photographed images.

To evaluate the safety of Surgi shield application, the vital signs, complete blood count, routine blood, routine chemistry, urine analysis, an electrocardiogram, and a chest X-ray were checked preoperatively and at 1 week postoperatively in all patients. All abnormal symptoms or signs and abnormal laboratory or imaging results were collected and analyzed.

\section{Statistical analysis}

Statistical analysis was performed using the SPSS ver. 13.0 (SPSS Inc., Chicago, IL, USA). The statistical significance of hemostasis was analyzed using the McNemar chi-square test. A Wilcoxon signed rank test was used to examine the difference of wound healing including mucosa edema, infection, crusting, and granulation at each time point. The statistical advantage of postoperative adhesion was analyzed using the McNemar test. $P$-value less than 0.05 was considered statistically significant.

\section{RESULTS}

A total 33 patients (26 men, 7 women) with a mean \pm SD age of $43.03 \pm 13.13$ years completed the clinical trial. There was no statistically significant difference in the preoperative LundMackay CT score between the Surgi shield applied side (7.30土 $2.59)$ and the control side $(7.27 \pm 2.43)(P=0.871$, Wilcoxon signed rank test) (Table 3$)$.

Table 3. Preoperative Lund-Mackay score between the active (Surgi shield ${ }^{\star}$ ) side and the control (no intervention) side

\begin{tabular}{lccc}
\hline & Surgi shield & Control & $P$-value \\
\hline Maxillary sinus & $1.42 \pm 0.56$ & $1.27 \pm 0.63$ & 0.132 \\
Anterior ethmoid sinus & $1.55 \pm 0.51$ & $1.58 \pm 0.50$ & 0.655 \\
Posterior ethmoid sinus & $1.15 \pm 0.67$ & $1.18 \pm 0.68$ & 0.317 \\
Frontal sinus & $1.09 \pm 0.91$ & $1.06 \pm 0.90$ & 0.782 \\
Sphenoid sinus & $0.48 \pm 0.67$ & $0.45 \pm 0.71$ & 0.739 \\
Ostiomeatal complex & $1.64 \pm 0.78$ & $1.70 \pm 0.73$ & 0.317 \\
Total & $7.30 \pm 2.59$ & $7.27 \pm 2.43$ & 0.871 \\
\hline
\end{tabular}

Values are presented as mean $\pm S D$.

${ }^{*}$ D. med, Seoul, Korea. 


\section{Comparison of hemostasis effect}

The Boezaart Surgical Field Grading Scale at the baseline time point of 0 minute was not significant different between the Surgi shield applied sides and the control sides $(P=0.662)$. However, the distribution of scores was significantly different at postoperative 2, 4, 6, 8, and 10 minutes between the 2 groups (Table 4). Hemostasis was rapidly achieved on the Surgi shield applied side (Fig. 2). Bleeding control rate was defined as the proportion of patients whose bleeding grade checked using The Boezaart Surgical Field Grading Scale is 0 at each time point and was significantly better in the Surgi shield side as compared with the control side at 2 minutes (69.70\% vs. $36.36 \%, P=0.007), 4$ minutes ( $81.82 \%$ vs. $45.45 \%, P=0.004), 6$ minutes $(90.91 \%$ vs. $54.55 \%, P<0.001), 8$ minutes $(90.91 \%$ vs. $57.58 \%$, $P=0.001$ ), and 10 minutes (93.94\% vs. $54.55 \%, P<0.001$ ).

Postoperative incidence of adhesion formation and its severity Adhesion formation at the postoperative 1, 2, and 4 weeks for the Surgi shield applied side was observed in 2, 2, and 5 patients, respectively. And those at each time point were seen in 13,15 , and 17 patients, respectively in control group. There were significantly less adhesions on the Surgi shield applied side at all evaluation points $(P<0.05)$ (Table 5$)$.

Table 4. Boezaart scores at 0, 2, 4, 6, 8, and 10 minutes after completion of surgery

\begin{tabular}{|c|c|c|c|c|c|c|c|c|}
\hline \multirow{2}{*}{$\begin{array}{l}\text { Time } \\
\text { (min) }\end{array}$} & \multirow[b]{2}{*}{ Treatment } & \multicolumn{6}{|c|}{ Boezaart score } & \multirow[b]{2}{*}{$P$-value } \\
\hline & & 0 & 1 & 2 & 3 & 4 & $\begin{array}{l}\text { Control } \\
\text { rate }(\%)\end{array}$ & \\
\hline \multirow[t]{2}{*}{0} & Active & 9 & 18 & 3 & 3 & 0 & 27.27 & 0.662 \\
\hline & Control & 11 & 15 & 4 & 3 & 0 & 33.33 & \\
\hline \multirow[t]{2}{*}{2} & Active & 23 & 8 & 1 & 1 & 0 & 69.70 & 0.007 \\
\hline & Control & 12 & 13 & 6 & 2 & 0 & 36.36 & \\
\hline \multirow[t]{2}{*}{4} & Active & 27 & 5 & 0 & 1 & 0 & 81.82 & 0.004 \\
\hline & Control & 15 & 11 & 6 & 1 & 0 & 45.45 & \\
\hline \multirow[t]{2}{*}{6} & Active & 30 & 2 & 0 & 1 & 0 & 90.91 & $<0.001$ \\
\hline & Control & 18 & 9 & 5 & 1 & 0 & 54.55 & \\
\hline \multirow[t]{2}{*}{8} & Active & 30 & 2 & 1 & 0 & 0 & 90.91 & 0.001 \\
\hline & Control & 19 & 10 & 4 & 0 & 0 & 57.58 & \\
\hline \multirow[t]{2}{*}{10} & Active & 31 & 1 & 1 & 0 & 0 & 93.94 & $<0.001$ \\
\hline & Control & 18 & 14 & 1 & 0 & 0 & 54.55 & \\
\hline
\end{tabular}

Although treatment including adhesiolysis was not required in patients with adhesion grades less than grade $(G) 1$, grades higher than G2 were considered to require treatment during the postoperative periods. Adhesion formation greater than G2 was observed in only 1 case at the postoperative 4 weeks in the Surgi shield applied side, while those at 1,2, and 4 weeks were seen in 4, 5, and 10 cases, respectively in control side. Adhesion was less severe on the Surgi shield applied side than on the control side at each evaluation time points $(P<0.05)$.

In addition, the severity of preoperative paranasal inflammation evaluated by Lund-Mackay CT staging system was not correlated with the incidence of postoperative adhesion formation $(P=0.495)$ (Table 6).

\section{Comparison of wound healing}

The degree of mucosal edema, infection, crusting, or granulation tissue formation assessed with the endoscopic features in the Surgi shield applied side was not significantly different from that of the control side at all evaluation points $(P>0.05$; Wilcoxon signed rank test) (Table 7).

\section{Postoperative safety evaluation of Surgi shield}

Laboratory results checked preoperatively and at 1 week post-

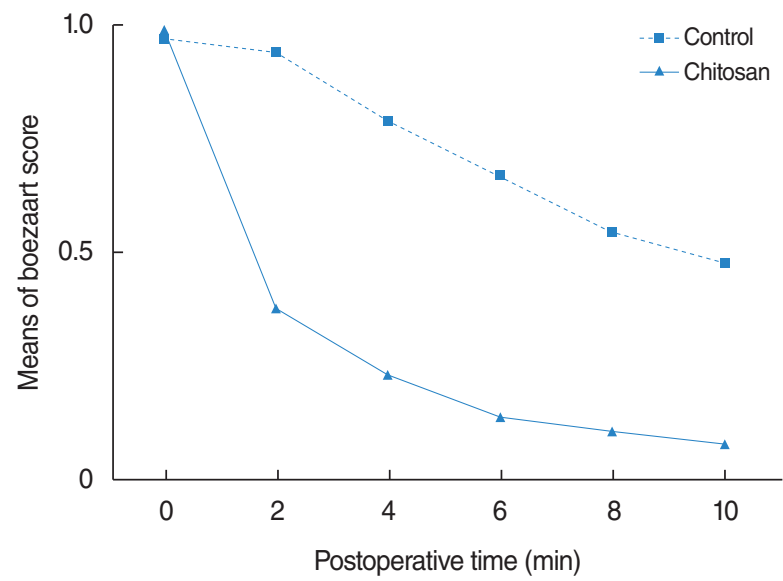

Fig. 2. Mean value of Boezaart scores after completion of surgery. Hemostasis was more rapidly achieved on the Surgi shield (chitosan; D. med, Seoul, Korea) applied side (solid line) than on the control side (dotted line) from 2 minutes after application of Surgi shield $(P<0.05)$

Table 5. Number of patients with adhesions on the active (Surgi shield*) side compared to the control (no intervention) side at 1st, 2nd, and 4th weeks

\begin{tabular}{|c|c|c|c|c|c|c|c|c|c|}
\hline \multirow{2}{*}{$\begin{array}{l}\text { Postoperative } \\
\text { follow-up (wk) }\end{array}$} & \multicolumn{4}{|c|}{ Surgi shield } & \multicolumn{4}{|c|}{ Control } & \multirow{2}{*}{$P$-value } \\
\hline & Go & G1 & G2 & G3 & GO & G1 & G2 & G3 & \\
\hline $1 s t$ & 31 & 2 & 0 & 0 & 20 & 9 & 3 & 1 & 0.001 \\
\hline 2nd & 31 & 2 & 0 & 0 & 18 & 10 & 4 & 1 & $<0.001$ \\
\hline 4th & 28 & 4 & 0 & 1 & 16 & 7 & 6 & 4 & $<0.001$ \\
\hline
\end{tabular}

G, grade.

${ }^{*}$ D.med, Seoul, Korea. 
Table 6. The incidence of adhesion formation in the active (Surgi shield ${ }^{\star}$ ) and control (no intervention) sides according to the preoperative Lund-Mackay scores

\begin{tabular}{|c|c|c|c|c|c|c|c|c|c|}
\hline & & & & & & & & & \\
\hline & G0 & G1 & G2 & G3 & G0 & G1 & G2 & G3 & \\
\hline CT score & & & & & & & & & 0.495 \\
\hline $0-3$ & 2 & 0 & 0 & 0 & 2 & 0 & 0 & 0 & \\
\hline $4-7$ & 14 & 1 & 0 & 0 & 9 & 6 & 1 & 1 & \\
\hline 8-12 & 15 & 1 & 0 & 0 & 7 & 4 & 3 & 0 & \\
\hline
\end{tabular}

G, grade.

*D. med, Seoul, Korea.

Table 7. Frequencies of ordinal scale scores for parameters of wound healing at 1 st, 2 nd, and 4 th weeks

\begin{tabular}{llccr}
\hline $\begin{array}{l}\text { Postoperative } \\
\text { follow-up (wk) }\end{array}$ & Wound healing & Surgi shield* & Control & $P$-value \\
\hline 1st & Mucosa edema & $0.73 \pm 0.45$ & $0.73 \pm 0.45$ & $>0.999$ \\
& Infection & 0 & 0 & $>0.999$ \\
& Crusting & $0.97 \pm 0.39$ & $0.91 \pm 0.38$ & 0.157 \\
& Granulation & $0.09 \pm 0.29$ & $0.09 \pm 0.29$ & $>0.999$ \\
2nd & Mucosa edema & $0.79 \pm 0.42$ & $0.82 \pm 0.39$ & 0.655 \\
& Infection & $0.03 \pm 0.17$ & $0.06 \pm 0.24$ & 0.317 \\
& Crusting & $0.48 \pm 0.51$ & $0.52 \pm 0.51$ & 0.564 \\
& Granulation & $0.18 \pm 0.39$ & $0.18 \pm 0.39$ & $>0.999$ \\
4th & Mucosa edema & $0.64 \pm 0.55$ & $0.73 \pm 0.52$ & 0.083 \\
& Infection & $0.06 \pm 0.24$ & $0.09 \pm 0.29$ & 0.564 \\
& Crusting & $0.09 \pm 0.29$ & $0.12 \pm 0.33$ & 0.317 \\
& Granulation & $0.18 \pm 0.39$ & $0.24 \pm 0.44$ & 0.414 \\
\hline
\end{tabular}

Values are presented as mean $\pm S D$.

${ }^{*}$ D. med, Seoul, Korea.

operatively showed no statistically significant difference. No adverse side effects were noted in the patient series.

\section{DISCUSSION}

This randomized study showed that Surgi shield containing chitosan achieved rapid hemostasis immediately and prevented adhesion formation in patients who underwent ESS. In addition, this agent had no adverse effects on wound healing compared with no treatment alone.

In this study, the complete hemostasis rate at 2, 4, 6, 8, and 10 minutes was $69.70 \%, 81.82 \%, 90.91 \%, 90.91 \%$, and $93.94 \%$ in the Surgi shield applied sides and $36.36 \%, 15.45 \%, 54.55 \%$, $57.58 \%$, and $54.55 \%$, respectively in the control sides. Complete hemostasis was rapidly achieved in the Surgi shield applied side compared with no treatment control side from 2 minutes after application of Surgi shield. A number of controlled animal and preclinical human trials have demonstrated potent hemostatic abilities of chitosan. Klokkevold et al. [16,17] performed bilateral tongue incisions in some rabbit models to evaluate the effect of chitosan on hemostasis and reported that topical application of chitosan to lingual incisions showed a $32 \%-43 \%$ im- provement in bleeding time as compared with controls. Valentine et al. [18] investigated the hemostatic properties of chitosan gel in the sheep CRS model by creating a standardized mucosal injury to the anterior ethmoid complex. They demonstrated that the chitosan gel applied side was significantly more hemostatic at 2, 4, and 6 minutes after injury compared with the control sides. They also evaluated the hemostatic efficacy of chitosan gel in patients with medically refractory CRS who underwent ESS and reported that the average time to hemostasis was significantly better on the chitosan gel applied side ( 2 minutes, $95 \%$ confidence interval [CI], 2-4 minutes) as compared with the control side (10 minutes, 95\% CI, $\geq 6$ minutes) [14]. Our study showed that chitosan gel (Surgi shield) has rapid hemostatic ability after application to the surgical field, achieving complete hemostasis in $90.91 \%$ of the Surgi shield applied sides by 6 minutes, which is consistent with previous studies. The mechanism of hemostasis initiated by chitosan gel is not known. Chitosan have been known to initiate hemostasis independent of platelets or coagulation factors [19], and scanning electron microscopy has shown that chitosan alters red blood cell morphology and increases the affinity between red blood cells [16]. Therefore, the hemostatic property of chitosan may be explained through interaction with erythrocytes, linking them together to establish a cellular clot or hemostatic plug.

The present study also showed the effect of chitosan gel on preventing postoperative adhesion formation. Adhesion occurs frequently after ESS and is the most common reason for revision surgery. Previous studies reported the variable incidence of adhesion formation after ESS. Some studies reported $11 \%$ incidence when only patients with significant scarring was included; however, others have shown $54 \%$ incidence when all adhesions are included regardless of its significance [6]. Adhesiolysis is not usually required in patients with mild adhesion but is needed in patients with moderate to severe adhesions during the postoperative periods. Current strategies for adhesion prevention in the sinonasal cavities include mucosal preservation technique, meticulous hemostasis, frequent postoperative careful debridement, topical adhesion barrier agents and some nasal packing. In this study, the overall percentage of adhesions in the control sides was $51 \%$ and was at the higher end of the reported range of the previous literature $(11 \%-54 \%)$. In addition, adhesion 
formation greater than G2, which often needs to be treated, was frequently observed in $30 \%$ of the control sides. In contrast, in the chitosan gel applied sides, the overall percentage of adhesion formation was $15 \%$ and adhesion greater than G2 was observed in only 1 case $(3 \%)$, showing preventing effect of adhesion formation of this product. This study attempted to assess the effect of preoperative Lund-Mackay CT scores on the incidence of postoperative adhesion formation. The severity of preoperative paranasal inflammation did not increase the incidence and degree of adhesion formation. Therefore, these findings could suggest that chitosan gel effectively reduce postoperative adhesion formation regardless of the severity of preoperative paranasal inflammation. Previous studies also have shown the antiadhesion properties of chitosan gel in animal and human abdominal and pelvic studies [20-22]. In the area of nasal cavity, Athanasiadis et al. [23] evaluated the effect on adhesion formation of chitosan gel in a sheep model of CRS, using a standardized mucosal injury to the lateral nasal wall and ethmoid region, and showed that chitosan significantly reduced the adhesion formation. And other study also revealed that chitosan gel is an effective agent to prevent adhesion formation in patients who underwent ESS [14]. The mode of action has not been fully elucidated. Bleeding and wound healing are closely related. After hemostasis, subsequent blood clots and fibrinous exudates secreted by injured tissue together induce fibroblast migration with subsequent collagen deposition and fibrous adhesion formation over the next 3-5 days [24], and development of fibrous adhesions depends on the balance of fibrinolysis to fibroblast migration, proliferation, and collagen deposition. In summarizing the results of previous study, chitosan most likely acts by providing a physical barrier separating injured mucosal surfaces and a rapid hemostasis until re-epithelialization and reciliation occurs, as well as potentially inhibiting fibroblast migration, proliferation, and collagen deposition, despite different preparations of chitosan $[22,23,25]$.

Hemostatic gels and some nasal packing materials have been shown to negatively impact the wound healing process with increased granulation tissue and adhesion formation [26-28]. However, chitosan gel additionally has been known to have no adverse effect on wound healing. No adverse impact on wound healing process was also found in this study because the postoperative degree of mucosal edema, infection, crusting, and granulation tissue formation in the chitosan gel applied side was comparable to that of the control side. Some researchers reported that chitosan gel has no adverse effect on the endoscopic or microscopic features of wound healing $[14,23]$. Therefore, chitosan gel significantly achieved rapid hemostasis immediately and reduced postoperative adhesion formation after ESS without an adverse effect on wound healing process. In addition, there was no adverse event in this patient series. Chitosan is a natural polymer obtained from chitin found in many natural sources including the cell walls of fungi, the exoskeletons of arthropods such as crustaceans (e.g., crabs, lobsters, and shrimps) and insects, the radulae of molluscs, and the beaks and internal shells of squid and octopuses. It has a low toxicity and is inert in the gastrointestinal tract of mammals. Currently, chitosan is used as a preservative to foods, an antimicrobial coating on fruits and vegetables for human consumption, a coating for seeds before planting, and a hydrating cosmetic product as well as an additive to shampoos and toothpaste [29]. Previous researcher evaluated the safety of chitosan gel in neurosurgical sheep model, chitosan gel was proven to be safe and nontoxic to neural tissue and is comparable to Gelfoam, as judged by postoperative magnetic resonance imaging scans and histological analysis [30].

This study has some limitations. First, this study was to evaluate the short-term clinical effect of Surgi shield containing chitosan on hemostasis and wound healing after ESS. Second, Merocel was used to prevent the early bleeding after evaluating the quality of the surgical field regarding bleeding and visibility. We initially planned to evaluate the unilateral effect of Surgi shield without using Merocel. However, we have changed our protocol according to the recommendation of The Korea Food and Drug Administration to use Merocel as a reference.

Surgi shield containing chitosan significantly reduced postoperative adhesion formation and achieved rapid hemostasis immediately after ESS without adverse side effects. These findings suggest that this agent can be used safely to obtain better outcomes in patients who underwent ESS.

\section{CONFLICT OF INTEREST}

No potential conflict of interest relevant to this article was reported.

\section{ACKNOWLEDGEMENTS}

This research was supported by Basic Science Research Program through the National Research Foundation of Korea (NRF) funded by the Ministry of Education (No. NRF-2013R1A1A4 A01010519) and by a grant of the Korean Health Technology R\&D Project, Ministry of Health \& Welfare, Republic of Korea (HI14C2161).

\section{REFERENCES}

1. Lazar RH, Younis RT, Long TE. Functional endonasal sinus surgery in adults and children. Laryngoscope. 1993 Jan;103(1 Pt 1):1-5.

2. May M, Levine HL, Mester SJ, Schaitkin B. Complications of endoscopic sinus surgery: analysis of 2108 patients. Incidence and prevention. Laryngoscope. 1994 Sep;104(9):1080-3.

3. Shone GR, Clegg RT. Nasal adhesions. J Laryngol Otol. 1987 Jun; 101(6):555-7. 
4. Vleming M, Middelweerd RJ, de Vries N. Complications of endoscopic sinus surgery. Arch Otolaryngol Head Neck Surg. 1992 Jun; 118(6):617-23.

5. White A, Murray JA. Intranasal adhesion formation following surgery for chronic nasal obstruction. Clin Otolaryngol Allied Sci. 1988 Apr;13(2):139-43.

6. Bugten V, Nordgard S, Skogvoll E, Steinsvag S. Effects of nonabsorbable packing in middle meatus after sinus surgery. Laryngoscope. 2006 Jan;116(1):83-8.

7. Kuhn FA, Citardi MJ.Advances in postoperative care following functional endoscopic sinus surgery. Otolaryngol Clin North Am. 1997 Jun;30(3):479-90.

8. Levi M, van der Poll T, Buller HR. Bidirectional relation between inflammation and coagulation. Circulation. 2004 Jun;109(22):2698704.

9. Azad AK, Sermsintham N, Chandrkrachang S, Stevens WF. Chitosan membrane as a wound-healing dressing: characterization and clinical application. J Biomed Mater Res B Appl Biomater. 2004 May;69(2): 216-22.

10. Azab AK, Doviner V, Orkin B, Kleinstern J, Srebnik M, Nissan A, et al. Biocompatibility evaluation of crosslinked chitosan hydrogels after subcutaneous and intraperitoneal implantation in the rat. $\mathrm{J}$ Biomed Mater Res A. 2007 Nov;83(2):414-22.

11. Rabea EI, Badawy ME, Stevens CV, Smagghe G, Steurbaut W. Chitosan as antimicrobial agent: applications and mode of action. Biomacromolecules. 2003 Nov-Dec;4(6):1457-65.

12. Illum L. Chitosan and its use as a pharmaceutical excipient. Pharm Res. 1998 Sep;15(9):1326-31.

13. Luppi B, Bigucci F, Cerchiara T, Zecchi V. Chitosan-based hydrogels for nasal drug delivery: from inserts to nanoparticles. Expert Opin Drug Deliv. 2010 Jul;7(7):811-28.

14. Valentine R, Athanasiadis T, Moratti S, Hanton L, Robinson S, Wormald PJ.The efficacy of a novel chitosan gel on hemostasis and wound healing after endoscopic sinus surgery. Am J Rhinol Allergy. 2010 Jan-Feb;24(1):70-5.

15. Boezaart AP, van der Merwe J, Coetzee A. Comparison of sodium nitroprusside- and esmolol-induced controlled hypotension for functional endoscopic sinus surgery. Can J Anaesth. 1995 May;42(5 Pt 1):373-6.

16. Klokkevold PR, Fukayama H, Sung EC, Bertolami CN. The effect of chitosan (poly-N-acetyl glucosamine) on lingual hemostasis in heparinized rabbits. J Oral Maxillofac Surg. 1999 Jan;57(1):49-52.

17. Klokkevold PR, Lew DS, Ellis DG, Bertolami CN. Effect of chitosan on lingual hemostasis in rabbits. J Oral Maxillofac Surg. 1991 Aug; 49(8):858-63.
18. Valentine R, Athanasiadis T, Moratti S, Robinson S, Wormald PJ.The efficacy of a novel chitosan gel on hemostasis after endoscopic sinus surgery in a sheep model of chronic rhinosinusitis. Am J Rhinol Allergy. 2009 Jan-Feb;23(1):71-5.

19. Yang J,Tian F, Wang Z,Wang Q, Zeng YJ, Chen SQ. Effect of chitosan molecular weight and deacetylation degree on hemostasis. J Biomed Mater Res B Appl Biomater. 2008 Jan;84(1):131-7.

20. Cetin M,Ak D, Duran B, Cetin A, Guvenal T, Yanar O. Use of methylene blue and $\mathrm{N}, \mathrm{O}$-carboxymethylchitosan to prevent postoperative adhesions in a rat uterine horn model. Fertil Steril. 2003 Sep;80 Suppl 2:698-701.

21. Kennedy R, Costain DJ, McAlisterVC, Lee TD. Prevention of experimental postoperative peritoneal adhesions by N,O-carboxymethyl chitosan. Surgery. 1996 Nov;120(5):866-70.

22. Zhou J, Elson C, Lee TD. Reduction in postoperative adhesion formation and re-formation after an abdominal operation with the use of N, O: carboxymethyl chitosan. Surgery. 2004 Mar;135(3):307-12.

23. Athanasiadis T, Beule AG, Robinson BH, Robinson SR, Shi Z, Wormald PJ. Effects of a novel chitosan gel on mucosal wound healing following endoscopic sinus surgery in a sheep model of chronic rhinosinusitis. Laryngoscope. 2008 Jun;118(6):1088-94.

24. Davey AK, Maher PJ. Surgical adhesions: a timely update, a great challenge for the future. J Minim Invasive Gynecol. 2007 Jan-Feb; 14(1):15-22.

25. Risbud M, Hardikar A, Bhonde R. Growth modulation of fibroblasts by chitosan-polyvinyl pyrrolidone hydrogel: implications for wound management? J Biosci. 2000 Mar;25(1):25-31.

26. Maccabee MS, Trune DR, Hwang PH. Effects of topically applied biomaterials on paranasal sinus mucosal healing. Am J Rhinol. 2003 Jul-Aug;17(4):203-7.

27. Chandra RK, Conley DB, Haines GK 3rd, Kern RC. Long-term effects of FloSeal packing after endoscopic sinus surgery. Am J Rhinol. 2005 May-Jun;19(3):240-3.

28. Shoman N, Gheriani H, Flamer D, Javer A. Prospective, doubleblind, randomized trial evaluating patient satisfaction, bleeding, and wound healing using biodegradable synthetic polyurethane foam (NasoPore) as a middle meatal spacer in functional endoscopic sinus surgery. J Otolaryngol Head Neck Surg. 2009 Feb;38(1):112-8.

29. Kurita K. Chitin and chitosan: functional biopolymers from marine crustaceans. Mar Biotechnol (NY). 2006 May-Jun;8(3):203-26.

30. Rajiv S, Harding M, Bassiouni A, Jardeleza C, Drilling A, James C, et al. The efficacy and safety of chitosan dextran gel in a burr hole neurosurgical sheep model. Acta Neurochir (Wien). 2013 Jul;155(7): 1361-6. 